\title{
OS PARTIDOS POLÍTICOS E A REFORMA POLÍTICA POSSÍVEL PARA O BRASIL
}

\author{
Mário Lúcio Quintão Soares ${ }^{1}$
}

Artigo elaborado a partir de texto direcionado para os debates no Seminário sobre a Reforma Política, realizado pelo Conselho Federal da OAB, entre 16 e 19 de novembro de 2010.

\begin{abstract}
O Analfabeto Político
Bertolt Brecht

O pior analfabeto é o analfabeto político. Ele não ouve, não fala, nem participa dos acontecimentos políticos. Ele não sabe que o custo de vida, o preço do feijão, do peixe, da farinha, do aluguel, do sapato e do remédio dependem das decisões políticas. O analfabeto político é tão burro que se orgulha e estufa o peito dizendo que odeia a política. Não sabe o imbecil que, da sua ignorância política, nasce a prostituta, o menor abandonado, e o pior de todos os bandidos, que é o político vigarista, pilantra, corrupto e lacaio das empresas nacionais e multinacionais.
\end{abstract}

\section{INTRODUÇÃO}

A discussão da reforma política torna-se o ponto central da agenda de mudanças estruturais necessárias ao avanço da democracia nacional.

As propostas de reforma política, apresentadas ao Congresso Nacional, resumem-se em questões pontuais e casuísticas ${ }^{2}$, aplicáveis a cada pleito eleitoral e jamais repensam os fundamentos da legitimidade democrática, que perpassam pela crise de representatividade dos agentes políticos e dos partidos políticos brasileiros.

Indaga-se sobre a dimensão de reformas políticas no Estado democrático de direito. Ora, pretende-se garantir que a representação política seja cada vez mais democrática, pelo que a sua ampliação e aperfeiçoamento conduzem ao desafio de se transformar a democracia em um conjunto de interações iterativas entre representantes e representados, desenvolvidas em um contexto decisório contínuo e institucionalizado.

\footnotetext{
1 Mestre e Doutor em Direito Constitucional pela Faculdade de Direito da UFMG.Professor de Direito Constitucional, Direito Eleitoral e Direito Comunitário dos Cursos de Doutorado, Mestrado e Bacharelado da Faculdade Mineira de Direito da Puc/Minas. Presidente do Centro de Estudos de Direito Público.VicePresidente da Comissão de Estudos Constitucionais do Conselho Federal da OAB. Conselheiro Federal da $\mathrm{OAB} / \mathrm{MG}$.

2 As mudanças eleitorais, aprovadas pelos congressistas brasileiros,sempre demarcaram-se como pontuais, pois as alterações mais profundas e impactantes originaram-se do TSE e STF.
}

Revista da Faculdade Mineira de Direito, v.13, n. 25, jan./jun. 2010 - ISSN 1808-9429. 71 
A segunda indagação é como fazê-lo? Fishkin sugere que se transformem as casas legislativas em "cidades mágicas". Ou seja, em espaços públicos de deliberação políticas que permitam e incentivem a interação entre representação proporcional e participação políticas, que facultem aos cidadãos a interlocução de suas preferências perante os legisladores e que lhes garantam o acompanhamento e o monitoramento permanente dos movimentos de seus representantes(Fátima Anastásia e Felipe Nunes, 2006:18) ${ }^{3}$

A crise do sistema de representação proporcional, que se acentuou no ocaso do século passado, problematiza os anacronismos e as mistificações de um Estado representativo sustentado em partidos políticos que pretendem, em suas deliberações, englobar interesses plurais da sociedade.

Não obstante, o papel das novas minorias sociais, a ascensão de novos estratos sociais, o esvaziamento ideológico dos partidos e a partidarização da representação local de interesses colocam em xeque a estabilidade do sistema democrático.

\section{O SIGNIFICADO E A LEGITIMIDADE DOS PARTIDOS POLÍTICOS}

Os partidos políticos se assemelham às partes processuais ante o tribunal, como se pode verificar a partir da raiz etimológica comum das nomenclaturas:partidos e partes, o que não é uma casualidade histórica. ${ }^{4}$

Além disso, a função primária dos partidos políticos no processo político está na fundamentação teórica de seu discurso ou de seu programa, i.e., nas suas alegações.

O deputado, que chega ao parlamento, graças às eleições organizadas por partidos é, em certo sentido, um advogado com poder geral e amplo, que, entretanto, desde a institucionalização dos partidos políticos no decorrer do século $\mathrm{XX}$, ao submeter-se à democracia dos partidos, deve justificar suas alegações perante o povo (Kriele:1980:455 et seq.).

Constata-se, portanto, a incompatibilidade entre a democracia de partidos,em sua estrutura fundamental, e a democracia liberal representativa. Em sua essência, a primeira nada mais é do que uma forma racionalizada da democracia plebiscitária ou um sucedâneo da democracia direta no Estado territorial moderno (Leibholz: 1989:321).

Até o século XIX, os partidos políticos, sob o paradigma da democracia liberal representativa, vicejavam, à margem do ordenamento jurídico ${ }^{5}$.

3 Artigo Reforma da Representação de Leonardo Avritzer in Reforma Política do Brasil, Coletânea org. por Leonardo Avritzer e Fátima Anastásia, Belo Horizonte: Editora UFMG, 2006.

4 Vide minha obra Teoria do Estado, $3^{\text {a }}$ Edição. São Paulo: Editora Atlas,2008, p.254.

Revista da Faculdade Mineira de Direito, v.13, n. 25, jan./jun. 2010 - ISSN 1808-9429. 72 
De acordo com Bluntschli, o Direito Público, da época, com seu sistema de competências e obrigações, nada sabia ${ }^{6}$ a seu respeito (1862:718).

O Estado liberal de direito sempre rejeitou os partidos políticos, dadoo seu caráter de instituições extralegais ou extraconstitucionais, como parte da constituição viva, mas sem lugar na constituição escrita. ${ }^{7}$

Os titulares dos órgãos do poder político se limitavam a exercer o papel de meros núncios ou mandatários a título imperativo.

O reconhecimento da natureza representativa do mandato só ocorreu com o estabelecimento de mecanismos democráticos para a sua designação.

Neste paradigma, a representação demoliberal era mero instrumento de emancipação do homem burguês, ao enfatizar sua liberdade pessoal.

Assim, o representante, uma vez eleito, só tinha compromisso com sua consciência, supondo-se livre e desembaraçado dos vínculos de sujeição a grupos, organizações partidárias e forças sociais ${ }^{8}$.

Todavia, os partidos políticos demonstraram sua eficiência, mesmo no liberalismo, como mecanismos eficazes da opinião pública e da alternância democrática de poder, adquirindo matizes ideológicos diversificados.

Para Neumann, desde então, há ambigüidade na função dos partidos políticos na democracia, ao permitir, frequentemente, a representação de interesses particulares, como se fossem interesses nacionais e, simultaneamente, ao evitar a dominação total dos interesses nacionais pelos particulares (1964:13).

Sob o ângulo sociológico, os partidos políticos são relações associativas, baseadas em recrutamento (formalmente livre), visando proporcionar poder a seus dirigentes no âmbito de uma associação e, por meio disso, a seus membros ativos, as oportunidades ideais ou materiais de realizar fins objetivos e/ou de obter vantagens pessoais (Weber 1991:188, v. I.).

No Estado territorial moderno, a contínua democratização, radical e igualitária, impôs a institucionalização dos partidos políticos, como organizações políticas necessárias à

5 Denominados ligas eleitorais ou união de eleitores.

6 As constituições democráticas do século XX continuaram, em princípio, a preservar esta conjuração de silêncio sobre os partidos políticos.

7 Conforme Rousseau, tratava-se de categorias intermediárias, incompatíveis com o princípio da soberania popular.

8 Este mandato livre do deputado deriva, historicamente, do poder judicial outorgado pela parte ao seu advogado (Kriele: 1980:456).

Revista da Faculdade Mineira de Direito, v.13, n. 25, jan./jun. 2010 - ISSN 1808-9429. 73 
emancipação política do cidadão no âmbito da democraciade massas, acoplada ao Estado social de direito 9 .

Ampliou-se a participação política, como forma de cooptação social ou inserção social de segmentos marginalizados.

Surgiram novos partidos políticos para captar a formação da vontade da opinião pública e refletir as transformações sociais, propiciando nova conotação para a democracia: regime político no qual o povo se manifesta na realidade política como uma totalidade ideal.

Simultaneamente, desencadeou-se um processo de parlamentarização dos sistemas políticos, decorrente da ampliação do direito de sufrágio e do aumento da atividade parlamentar dos partidos políticos, implicando a formação de governos responsáveis e representativos.

Nesse contexto, os partidos adquiriram novo significado, convertendo-se emorganizações políticas sem as quais a democracia de massas não poderia ter suas expectativas satisfeitas.

O mandato parlamentar deixou de ter poderes amplos e irrestritos, ao condicionar-se às diretrizes políticas partidárias (Leibholz: 1989: 387).

Por outro lado, a degeneração do Estado social, lamentavelmente, propiciou condições para ascensão ao poder de governos totalitários com seus respectivos monopartidarismos, desmitificando a democracia de partidos.

Após a queda do totalitarismo nazi-fascista, os Estados constitucionais democráticos procuraram assegurar a estabilidade das instituições democráticas,por intermédio de regras específicas ou um 'ethos' para estruturação e atuação partidária, denominado tipos de controle.

Estes controles determinam os procedimentos adequados aos partidos políticos, no sentido dos limites legais e éticos para captação e organização da autêntica vontade popular.

- Com o controle de caráter ideológico-programático, ao impor severas restrições às manifestações ideológicas autocráticas inseridas em programas partidários, coibiu-se a constituição e as atividades de organizações políticas contrárias à ordem democrática.

\footnotetext{
9 A Constituição de Weimar foi uma das primeiras a mencionar, indiretamente, a existência dos partidos políticos, ao esclarecer que os funcionários não eram servidores de um partido, mas da comunidade (art.130, parágrafo $1^{\circ}$ ).
}

Revista da Faculdade Mineira de Direito, v.13, n. 25, jan./jun. 2010 - ISSN 1808-9429. 74 
- Com controle de caráter externo - ao determinar que as atividades partidárias se desenvolvam em observância à ordem pública, vedou-se o recurso à violência ou à propagação programática de idéias subversivas;

- O controle de caráter interno - ao exigir a democratização da estrutura partidária, procurou-se inibir o surgimento de lideranças carismáticas de caráter autoritário (Virga: 1967: 147 et seq.).

Quanto à natureza jurídica dos partidos políticos, esta deriva do fato que na democracia moderna a sociedade vê-se destinada a integrar-se de modo permanente ao aparelho ideológico estatal, como fonte legitimadora do poder.

Aos partidos atribuiu-se a função de aglutinar os interesses e mundividências de certas classes e grupos sociais, impulsionadores da vontade geral, captada com oportunidade.

Para Virga, os partidos políticos constituem-se em associações de pessoas com ideologia ou interesses comuns, que, mediante, uma organização estável ('partei- apparat'), pretendem exercer influência sobre as diretrizes políticas do Estado. São, ainda, órgãos do Estado, no que se refere às suas características de grupo eleitoral e de grupo parlamentar (1967: 243 et seq.).

Biscaretti di Ruffia refuta tal concepção, mesmo reconhecendo em sua atividade um exercício privativo de funções públicas, mas percebendo sua natureza jurídica como entes auxiliares do Estado, i.e., entidades tendentes a converterem-se em instituições (1974: 771 et seq).

Esta ideia de que os partidos políticos exercem funções de um órgão constitucional foi esposada, na Alemanha, por Leibholz ${ }^{10}$, contudo, doutrinariamente, além de não serem órgãos estatais ou constitucionais, os partidos não são corporações de direito público.

A constitucionalização dos partidos ou incorporação constitucional destes impõe que tais instituições políticas deixem de ser apenas uma realidade sociológica política ${ }^{11}$, jamais como órgãos do Estado, pois adquirem estatuto constitucional, configurados em direito subjetivo, direito político e liberdade fundamental.

Do estatuto subjetivo deriva sua caracterização como associações de direito privado às quais se reconhecem direitos fundamentais (Canotilho, 1998: 302 et seq.). ${ }^{12}$

10 Refere-se à participação dos partidos políticos na formação da vontade do povo como equivalente às funções de um órgão constitucional. Vide, nesse sentido, in Leibholz, Struktur-probleme der modern Demokratie.

11 Nesse sentido, os partidos representam as associações políticas organizadas para propiciar forma e eficácia a um poder de fato.

12

Revista da Faculdade Mineira de Direito, v.13, n. 25, jan./jun. 2010 - ISSN 1808-9429. 75 
Nessa linha de reflexão, os partidos políticos consistem em grupos de pessoas, organizadas em instituições políticas, dotadas de personalidade jurídica, com a finalidade de exercer ou de influenciar o poder do Estado para realizar total ou parcialmente um programa político de caráter geral.

Seguindo a melhor doutrina, o Direito Constitucional brasileiro considera os partidos políticos, no que tange à sua personalidade jurídica, pessoas jurídicas de direito privado ${ }^{13}$.

\section{JUSTIFICATIVAS PARA UMA REFORMA POLÍTICA NO BRASIL}

Preliminarmente, deve-se conceituar o Brasil como república presidencialista, federativa, com representação proporcional e multipartidarismo. Seu poder legislativo, no âmbito federal, apresenta-se como bicameral, com uma câmara dos deputados, eleita pelo sistema proporcional de listas abertas, ${ }^{14}$ e um Senado, escolhido pelo sistema majoritário. ${ }^{15}$

Tais características são tendentes à dispersão de poder entre os atores relevantes, garantem a participação institucionalizada das minorias e facultam a expressão da heterogeneidade e do pluralismo de sua complexa sociedade.

Portanto, no que se concerne ao eixo método de constituição das instâncias decisórias, o Brasil, formalmente, pode ser classificado com pertencente ao modelo consensual de democracia (Fátima Anastásia e Felipe Nunes, 2006:22). ${ }^{16}$

Mesmo não existindo um consenso com relação aos fins desejáveis, a identificação de problemas de governabilidade enseja a necessidade de uma reforma política no Brasil.

Percebe-se, no entanto, que lograram êxito tão somente as propostas de reforma política, que contaram com o apoio do Executivo (caso da reeleição); criadas, via judicialização, com a prática do ativismo judicial (caso da verticalização das coligações); ou responderam às demandas da opinião pública(caso da fidelidade partidária) e /ou pressões, via iniciativa popular, da sociedade civil(caso da Lei da Ficha Limpa).

A primeira premissa, a ser analisada, envolve os procedimentos legislativos, adotados nas eleições proporcionais brasileiras, os quais provocam distorções na representação e carecem ser modificados para garantira observância do princípio de isonomia política entre os cidadãos.

\footnotetext{
13 De acordo com o art. $17, \S 2^{\circ}$ da CR, os partidos políticos, após adquirirem personalidade jurídica, na forma da lei civil, registrarão seus Estatutos no Tribunal Superior Eleitoral. Daí, tais agremiações partidárias poderão ter direito a recursos do fundo partidário e acesso gratuito ao rádio e à televisão, na forma da lei.

14 Locus onde se fazem representar cada cidadão da federação.

15 Locus ondese fazem representar os estados federados(três por cada unidade federativa). 16 Op. cit., 2006.
}

Revista da Faculdade Mineira de Direito, v.13, n. 25, jan./jun. 2010 - ISSN 1808-9429. 76 
Os distritos eleitorais brasileiros equivalem aos estados da federação, tendo a Constituição vigente determinado um número mínimo de oito, e máximo de setenta representantes por cada distrito. Na prática, isso acarreta uma desproporção da representação dos cidadãos de São Paulo, de maior densidade populacional, em relação aos eleitores dos estados menos populosos, tais como Acre, Amapá e Roraima. ${ }^{17}$

A segunda premissa versa sobre a coincidência das eleições sem a necessidade de verticalização. ${ }^{18} \mathrm{Ou}$ seja, a casuística legislação eleitoral faculta a celebração de coligações para eleições proporcionais, gerando uma disjunção entre o sistema partidário eleitoral e o sistema partidário parlamentar. Tal fato debilita o caráter nacional dos partidos políticos, ao minar sua unidade e disciplina, mediante alianças espúrias que comprometem a qualidade da representação popular.

Temas polêmicos, como cláusula de barreira, ${ }^{19}$ que concebe um desempenho eleitoral mínimo para que os partidos participem do processo eleitoral e tenham acesso aos recursos do fundo partidário e tempo na televisão, já foram sepultados pelo STF. ${ }^{20}$

Demonstra-se inconstitucional esta cláusula, ao discriminar legendas que expressam correntes ideológicas essenciais para o jogo democrático, não obstante pretender reduzir o número de partidos políticos, dentre os quais as legendas de aluguel.

A aprovação de regras que estabeleçam o financiamento público das campanhas eleitorais deve ser retomada, pois inibe a prevalência do poder econômico nas disputas eleitorais, manifestado na maior possibilidade de eleição daquele candidato que abusa deste poder. Outra dúvida está na distribuição dos recursos entre os candidatos pelas direções partidárias, que pode privilegiar algumas candidaturas em detrimento de outras.

Em retrocesso das tradições republicanas, reinseriu-se o instituto da reeleição no sistema eleitoral brasileiro pela Emenda Constitucional $n^{\circ}$ 16, de 4 de junho de 1997, que acrescentou o $\S 5^{\circ}$ ao art. 14 da Constituição da República.

17 Consiste em legado da Ditadura Militar que distorce a representatividade da Câmara dos Deputados.

18 A nova redação do art. $17, \S 1^{\circ}$, da Constituição da República, ao dispor sobre o fim da obrigatoriedade da verticalização das coligações político-partidárias, incidiu sobre as eleições de 2010, segundo interpretação do STF na ADIN n ${ }^{\mathrm{o}} 3.685-8 / \mathrm{DF}\left(\mathrm{Rel}^{\mathrm{a}}\right.$. Min ${ }^{\mathrm{a}}$. Ellen Gracie, DJ de 10.8.2006).

19Esta cláusula de exclusão surgiu na Constituição outorgada de 1967,recebeu várias emendas, enão foi recepcionada pela Constituição vigente. Entretanto, ressuscitou, em 1995, com a Lei 9.096.

20 O Plenário do STF, em decisão unânime, no final de 2006, declarou a inconstitucionalidade de dispositivos da Lei 9.096/95 (Lei dos Partidos Políticos ) que instituíam a cláusula de barreira, no julgamento conjunto de duas ações diretas de inconstitucionalidade (ADIs 1351 e 1354), ajuizadas, respectivamente, pelo PCdoB e pelo PSC.

Revista da Faculdade Mineira de Direito, v.13, n. 25, jan./jun. 2010 - ISSN 1808-9429. 77 
A opção brasileira, manifesta na Constituição de 1891,pela não-reeleição decorreu da abominação do continuísmo governista, traço marcante do regime monárquico, que não se coaduna com a democracia.

Temido, historicamente, por suas características e desvios, o instituto da reeleição, nos âmbitos federal, estadual e municipal, enseja a influência nociva dos detentores de mandatos eletivos nas próprias campanhas eleitorais.

A legislação eleitoral vigente tenta, em vão, coibir o uso indevido do poder econômico e do poder político em benefício destes candidatos, pelo que merece uma modificação normativa radical, para viabilizar a igualdade de oportunidades entre os concorrentes, com a proibição da reeleição.

A restrição à divulgação e/ou controle democrático das pesquisas eleitorais seria uma medida salutar para impedir que a manipulação dos levantamentos de opinião sobre a intenção de voto possa influenciar nos resultados das eleições. ${ }^{21}$ Trata-se de uma restrição à liberdade de informação, que deve ser dimensionada, vez que não contribui para o aperfeiçoamento da democracia.

Um aspecto fundamental no sistema de representação proporcional impõe verificar a repercussão ideológica de seus sistemas, ao pretender promover a distribuição dos mandatos legislativos, segundo a representatividade dos partidos existentes.

Nesse arranjo político, o parlamento apresenta-se como um espelho das diversas e complexas forças políticas atuantes na sociedade. A priori, cabe ao legislador definir uma das três opções de sistema de listas que os partidos poderão submeter ao pleito, para se determinar o número de cadeiras a que farão jus, distribuídas entre seus candidatos.

A primeira opção, muito criticada, refere-se ao sistema da lista aberta, em que há o escrutínio de lista desordenada, com o eleitor tendo a opção de votar no partido ou no candidato de sua preferência. Tal escrutínio depende exclusivamente dos eleitores, pois se

21 Desde 1965, a regulação das pesquisas eleitorais se faz presente na legislação eleitoral brasileira. O Código Eleitoral trouxe consigo a regra de quinze dias anteriores à eleição como o período de restrição para a divulgação de prévias eleitorais (Lei 4.737/1965, art. 255). Tal medida, mantida e ampliada, após a redemocratização, em 1985, de forma casuística, limitou a proibição para o período dos 21 dias anteriores à eleição de 1986 (Lei 7.508/1986), para os 30 dias anteriores ao $1^{\circ}$ turno da eleição presidencial de 1989, e para os 10 dias anteriores ao $2^{\circ}$ turno (Lei 7.773/1989). Tão somente, em 1990, as restrições à divulgação seriam extirpadas da legislação(Resolução 16.402/1990). Contudo,em 1988, através de medidas judiciais ajuizadas pelos meios de produção e divulgação de pesquisas, com base no direito constitucional à liberdade de expressão e de informação, esta proibição foi suspensa e a divulgação sem restrição de tempo passou a nortear as pesquisas.

Revista da Faculdade Mineira de Direito, v.13, n. 25, jan./jun. 2010 - ISSN 1808-9429. 78 
inclina à eleição personalizada. Este sistema é utilizado no Brasil, na Finlândia, no Chile e na Polônia (JAIRO NICOLAU, 2006:133). ${ }^{22}$

A outra opção, que fascina a sociedade civil brasileira ${ }^{23}$, é o sistema da lista fechada, em que os eleitores votam em uma lista de candidatos preordenada pelo partido, cujo conteúdo é divulgado previamente ao eleitor. Apura-se o total de votos recebidos pela lista partidária, anotando-se que o partido ocupará o percentual das cadeiras correspondente ao percentual de votos obtidos pela lista partidária. Os candidatos situados nos primeiros lugares na lista serão considerados eleitos. Adotam este sistema Israel, Espanha, Portugal, Argentina, África do Sul e, desde 2006, a Itália.

Uma terceira opção engloba o sistema da lista flexível, em que os partidos estabelecem também a ordem dos candidatos antes das eleições, entretanto os eleitores podem votar em qualquer nome da lista. $\mathrm{O}$ voto dado na legenda confirma o ordenamento dos candidatos, definido pelos partidos. Caso um candidato obtenha um número significativo de votos, ${ }^{24}$ altera-se sua posição na lista. Esse sistema vê-se utilizado na Áustria, Holanda, Bélgica, Suécia, Dinamarca e Noruega (JAIRO NICOLAU, 2006:134).

Nesta linha de argumentação, há uma apologia do voto distrital, puro ou misto, como uma solução mágica para acentuar a representatividade política no Brasil. Trata-se de sistema de escolha do candidato adstrita à região definida por espaço geográfico eleitoral préestabelecido.

O voto distrital, em sua essência, permite uma maior identidade com a representação política, ao ensejar proximidade ou conhecimento do eleitor com o eleito, a fiscalização dos candidatos pela população local e menos candidatos no momento da escolha.

No voto distrital puro não existe o voto para candidatos de fora da região do eleitor e não se facilita a representação por categorias homogêneas de interesses, inclinando-se à diminuição de partidos políticos. No voto distrital misto, parte das vagas é escolhida pelo sistema distrital e a outra parte, pelo sistema proporcional.

O sistema distrital misto de superposição aglutina vetores dos dois grandes modelos eleitorais puros existentes: o majoritário e o proporcional. Para o componente majoritário do sistema, a circunscrição divide-se em distritos eleitorais, em cujo âmbito cada partido poderá lançar um candidato, elegendo-se um único parlamentar por cada distrito. Para a dimensão proporcional do modelo, cada partido apresenta uma lista fechada de candidatos.

22 Artigo Lista Aberta/Lista Fechada in in Reforma Política do Brasil, Coletânea org. por Leonardo Avritzer e Fátima Anastásia, Belo Horizonte: Editora UFMG, 2006.

23 Vide proposta de Reforma Política da OAB, sob a coordenação de Luiz Roberto Barroso.

Revista da Faculdade Mineira de Direito, v.13, n. 25, jan./jun. 2010 - ISSN 1808-9429. 79 
O eleitor, assim, terá direito a dois votos: o primeiro no candidato de sua preferência no âmbito do distrito; e o segundo, no partido político de sua preferência.

Dessa forma, na composição da Câmara dos Deputados, metade dos candidatos será eleita pelo voto distrital e a outra metade pelo voto proporcional, de acordo com a votação de cada partido.

O voto distrital puro foi adotado no Brasil,por duas vezes: uma, durante o Império, atrelado ao voto censitário; e outra, na República Velha, conspurcado pelo voto bico de pena. 25

No Império, a legislação dividia as antigas províncias em círculos eleitorais. Cada círculo só podia eleger um candidato, até 1860, quando, com alteração legislativa, permitiu-se eleger três representantes. Em 1904, durante a República Velha, a Lei Rosa e Silva adotou novas regras, segundo as quais, cada distrito podia apresentar até cinco candidatos e eleger três. Cada eleitor tinha o direito de votar três vezes e endereçar seus votos ao mesmo candidato. $^{26}$

O grande problema da reintrodução do voto distrital. ${ }^{27}$ Reside na tradição patrimonialista brasileira, que ainda transforma alguns município sem currais eleitorais, onde se manipula impunemente o voto dos eleitores, sob o olhar impotente da Justiça Eleitoral.

Ou seja, nestes municípios, a minoria não conseguirá assegurar representação no distrito em que for derrotada. Este voto distrital conduziria, portanto, ao bipartidarismo.

O voto facultativo, outra questão polêmica, consiste no discurso peculiar dos conservadores. Seu oposto é o voto obrigatório, em que a participação eleitoral não é deixada ao arbítrio do eleitor, mas determinada por lei, que, nessa perspectiva, prevê sanções no caso de não cumprimento.

As razões a favor ou contra o voto obrigatório podem ser classificadas em razões de princípio, que consideram o significado e o estatuto do ato de votar; e razões prudenciais, que observam os efeitos benéficos ou danosos da obrigatoriedade ou não da participação (CÍCERO ARAÚJO, 2006:87). ${ }^{28}$

24 Os critérios de contagem variam em cada país.

25 No ocaso do regime militar de 1964, a Emenda Constitucional n 22, de lavra de Comissão do Ministério da Justiça, ressuscitou a proposta do voto distrital misto. Entretanto, essa emenda Constitucional foi revogada, em 1985 , sem ter sido aplicada.

26 Esse sistema vigorou até 1930, quando Vargas pôs fim à República Velha e estabeleceu novas regras eleitorais. Em 1932, o primeiro Código Eleitoral brasileiro fez-se acompanhar pelo voto proporcional.

27 Há proposta do voto distrital, no Brasil, não obrigatório e, em dois turnos, em todos os níveis (municipal, estadual e federal), com os cidadãos usufruindo de igualdade de valor do voto, bem como controle sobre os seus representantes e efetivo da autoridade.

28 Artigo Voto obrigatório in Reforma Política do Brasil, Coletânea org. por Leonardo Avritzer e Fátima Anastásia, Belo Horizonte: Editora UFMG, 2006.

Revista da Faculdade Mineira de Direito, v.13, n. 25, jan./jun. 2010 - ISSN 1808-9429. 80 
O que existe no Brasil é a obrigatoriedade do cidadão alistar-se como eleitor, habilitando-se a votar. Isso não significa que seja obrigado a fazê-lo, pois pode abster-se, justificando a ausência, pode anular o voto ou votar em branco.

O voto obrigatório demonstra-se também como um procedimento político eficaz de Estado que, mesmo não eliminando a desigualdade política entre os eleitores, derivada da estrutura social, pelo menos a atenua.

A obrigatoriedade do alistamento eleitoral ainda desempenha um papel pedagógico para o fortalecimento da democracia brasileira.

Das propostas de reforma política, postas em discussão, devem ser priorizadas asque corrigem distorções no sistema de representação popular.

A sociedade brasileira, cética e indignada, exige uma ampla reforma política, mediante o resgate do princípio democrático, que se permeia, no primeiro momento, pela modificação estrutural da Justiça Eleitoral, e envolve a alteração radical da complexa legislação eleitoral, nos seguintes aspectos:

a) Elaboração de novo Código Eleitoral, estribado na legitimidade democrática;

b) Reestruturação da Justiça Eleitoral, a ser constituída por membros especializados, concursados e de caráter permanente;

c) Edição de regras eleitorais contínuas em detrimento de regras eleitorais casuísticas para cada pleito;

d) A aprovação de financiamento público de campanhas e a vedação de financiamento privado;

e) A busca de uma maior representatividade dos candidatos em consonância comum maior equilíbrio federativo entre as diversas regiões brasileiras, respeitando-se a identidade política, cultural e econômica de cada uma.

\section{REFERÊNCIAS}

FISHKIN, James S. in The voice of the people: public opinion and democracy. New Haven/London: Yale University Press, 1995.

KRIELE, Martín, in Introducción a la Teoría del Estado - Fundamentos Históricos de la Legitimidad del Estado Constitucional Democrático. Trad. de Eugênio Bulygin. Buenos Aires: Depalma, 1980.

LEIBHOLZ, Gerhard, in La rappresentazione nella democrazia. Milâo: Giuffrè, 1989.

Vide Bluntschli, in Deutsches Staats-Woerterbuch, Stuttgart und Leipzig:1862, v.VII.

Revista da Faculdade Mineira de Direito, v.13, n. 25, jan./jun. 2010 - ISSN 1808-9429. 81 
NEUMANN, Franz, The Democratic and the Authoritarian State. Essays in Political and Legal Theory. Londres: Free Press of Glencoe, 1964.

WEBER, Max. Economia e sociedade: fundamentos da sociologia compreensiva. Brasília:UNB, 1991.(V.I)/1999.(V.II).

VIRGA, Pietro, Diritto Costituzionale, 6ª Ed. Milão: Giuffrè, 1967.

BISCARETTI DE RUFIA, Paolo. Diritto Costituzionale. 10ª Ed. Nápoles: Carta Editrice Dott, Eugene Jovene, 1974.

CANOTILHO, José Joaquim Gomes. Direito Constitucional e Teoria Constitucional. $2^{\mathrm{a}}$ Ed. Coimbra: Almedina, 1998. 